\title{
Graduate nurses and nursing student's behaviour: Knowledge and attitudes toward smoking cessation
}

\author{
Lorna Moxham $^{\mathrm{a}, *}$, Trudy Dwyer ${ }^{\mathrm{b}}$, Kerry Reid-Searl ${ }^{\mathrm{b}}$ \\ a School of Nursing, Midwifery and Indigenous Health, University of Wollongong, Springfield Ave, Wollongong, NSW 2500, Australia \\ ${ }^{\mathrm{b}}$ Institute of Health and Social Science Research, CQUniversity, Bruce Hwy, Rockhampton, Qld 4701, Australia
}

\section{A R T I C L E I N F O}

Article history:

Accepted 29 November 2012

\section{Keywords:}

Tobacco cessation

Nurses

Health promotion

Role model

\begin{abstract}
S U M M A R Y
Background: Smoking remains the largest single cause of preventable mortality. In rural Australia where the incidence of smoking is higher, health is substantially worse than other Australians. Smoking cessation is difficult with many attempts made before success. Health professionals are in a prime position to assist smoking cessation but are failing to consistently assess tobacco use and assist patients quit. Nurses who form the largest cohort of health care professionals, should play a part in smoking cessation yet their influential role is hugely underutilised. Given the strategic place of nurses to advance the anti-smoking message during clinical interactions, data was needed on smoking rates as well as on smoking attitudes and behaviours.

Objectives: To determine the smoking rates and behaviour as well as attitudes of nurses toward assisting hospitalised patients to cease smoking.

Design: Descriptive survey research design.

Participants: Non-probability sampling of undergraduate nursing students $(\mathrm{n}=153)$ and graduate nursing students $(\mathrm{n}=64)$ from a regional nursing school in an Australian university.

Methods: Survey.

Results: Factor analysis revealed four clearly differentiated factors, non-smoker's rights, cessation beliefs, cessation attitudes and therapeutic relationships. Significant differences were present in nurse's perceptions of smoking rights across age categories but not for other factors, no significant gender differences were noted across categories, nor were significant differences noted between levels of nursing qualifications across categories however smoking status revealed significant differences in perceptions of rights.

Conclusions: Student and graduate nurses are aware that they are role models and that they have an influential role in modifying patient behaviour. When it comes to assisting patients to cease tobacco use, age and smoking status of nurses influence their actions. Nursing curriculums need to emphasise the role nurses play in smoking cessation and give them the tools they need to help patients QUIT.
\end{abstract}

(c) 2012 Elsevier Ltd. All rights reserved.

\section{Introduction}

Smoking is a leading cause of mortality and morbidity in Australia and the greatest burden on the health of Australian people (Australian Institute of Health and Welfare $\{$ AIHW, 2012 ). The health consequences of smoking are well documented with smokers having a lifespan ten years shorter than non smokers (Doll et al., 2004). About 1:5 cancer deaths are attributed to smoking and more than 10,000 Australians are diagnosed with a smoking-related cancer annually (Cancer Council Victoria, 2012).

Smoking is one of the leading causes of death and disability worldwide with about 1.3 billion people currently smoking. By 2030 smoking is expected to contribute to about 10 million deaths annually (Peto et al., 2000). Smoking is the most modifiable, non-genetic risk factor for coronary heart disease; 2-3 times greater than for non-smokers (Munafò

\footnotetext{
* Corresponding author. Tel.: +612 42392559.

E-mail address: Imoxham@uow.edu.au (L. Moxham).
}

et al., 2003). 3.1 million adults smoke in Australia (Australian Institute of Health and Welfare, 2012) with most aged 25-29. Of 14-19 year olds, $14 \%$ of boys and $16 \%$ of girls smoked daily (Australian Institute of Health and Welfare, 2012). It is estimated that up to 50\% of Indigenous Australian adults smoke. This group starts younger and has more difficulty giving up (Queensland Government, 2009). Annually about 3400 deaths and 30,450 hospitalisations are due to smoking with costs in Queensland alone more than \$137 million per annum (Queensland Health, 2004). In Central Queensland, the focus of this research, reports note (ABS 3218.0) that women and men have significantly higher ischaemic heart disease mortality rates than average (Central Public Health Unit Rockhampton, 1998) with hospital admissions high and costly (Moxham et al., 2000).

Nurses can adopt a global framework such as that outlined by The Ottawa Charter for Health Promotion (WHO, 1986) by empowering individuals to cease smoking.

Most smokers consider cessation during hospitalisation (Dunn, 1998) but abstinence is difficult (Attenbring et al., 2004). Health 
professionals need to increase knowledge about these challenges and actively help people achieve a healthier lifestyle (Talbot and Verrinder, 2005). Nurses have a great potential for influencing patients with Munafò et al. (2003) reporting on how a nurse led smoking cessation group received accolades for their SmokeStop sessions. Nurses are well placed to screen people for risk factors and offer health education and interventions (Mitchell et al., 2009; Hall et al., 2005). The National Institute for Health and Clinical Excellence (NICE) recommends that nurses consult patients about smoking cessation (Carlebach and Hamilton, 2009) and the 2006-2010 Queensland Drug Strategy suggests training health professionals in the delivery of quit smoking assistance (Queensland Government, 2009).

Little accurate information exists regarding the incidence of smoking amongst nurses and student nurses but given high proportions of females in nursing, rates could be high if they smoke the same as other women of similar age and socio-economic groups (Rowe and Clark, 2000). Research from the USA ( $n=91651)$ suggests 1:3 (34\%) smoked (Myers et al., 1987 cited in Hughes and Rissel, 1999).

Scanlon et al. (2008) argue that nurses should be involved in assisting smoking cessation. Hughes and Rissel (1999) examined attitudes amongst nursing staff $(\mathrm{n}=610)$ and found a correlation with personal smoking status. Smokers in health care settings are poor role models, hold attitudes that impede their ability to help patients quit, are less likely to provide cessation advice and have knowledge deficits (Hughes and Rissel, 1999). A study of mental health nurses $(n=289)$ attitudes towards smoking reported that non-smokers held stronger views about the health promotion role. Despite possessing skills and knowledge to deliver the quit smoking message they were less inclined to do so if they thought the individual had a right to smoke or where smoking facilitated therapeutic interactions (Dwyer et al., 2009).

Smoking behaviour of nursing students may have a profound effect on the implementation of smoking prevention activities once they become registered (Baron-Epel et al., 2004). Baron-Epel et al.'s (2004) Israeli study examining nursing students' perception of smoking prevention $(\mathrm{n}=782)$ found that smoking status exerted a marked influence on attitudes to smoking role modelling and prevention. Participants (22\%) who were current smokers were less likely to be active in smoking prevention (Baron-Epel et al., 2004). A US study describing the smoking beliefs of nursing students $(n=200)$ found non-smokers more likely to provide tobacco treatment interventions (Jenkins and Ahijevych, 2003). Where nursing students do provide health education, they express conflict and uncertainty about individual autonomy and tobacco use (Chalmers et al., 2003).

Few studies of the incidence of nursing students smoking have been conducted in Australia (Rowe and Clark, 2000). A study that examined 366 undergraduate nursing students' knowledge and attitudes about the impact of smoking found most participants $(n=86$; $24 \%$ ) who smoked began prior to commencing their degree (Rowe and Clark, 2000). The incidence of smoking in female participants was higher than in men and for females generally. Nurses cognitively isolated knowledge about the effects of smoking, not allowing it to influence their attitudes (Clark et al., 2003). Relative risk is underestimated and while smokers accept the links to ill health, they do not personally relate to it. Clark et al. (2003) concluded that nurse educators should place greater emphasis on smoking, smoking-related illness and the nurses' role in health promotion. Further nurse educators should investigate how to change undergraduate nursing student's attitudes towards smoking.

People living in rural, regional and remote Australia have poorer health and smoke more when compared to metropolitan counterparts (Australian Institute of Health and Welfare, 2012) and thus experience the negative health consequences (Australian Institute of Health and Welfare, 2012) yet have less access to health services to gain treatment. Dunn (1998) describes a paucity of research address these issues in rural areas which is particularly important due to a lack of specialist services to support smoking cessation.
Nurses constitute the largest component of the rural health care workforce (Gomm et al., 2002) and given their strategic placement to advance the anti-smoking message data is needed on smoking rates as well as on smoking attitudes and behaviours. This study describes rural nurses and nursing students' beliefs about tobacco smoking, their smoking behaviours and identifies factors associated with their role in smoking prevention.

\section{Aims}

The aims of the project were to gather data on nurses and nursing students smoking behaviour, knowledge and attitudes and to determine if graduate nursing students demonstrate greater knowledge and positive attitudes towards smoking cessation when compared to undergraduate students.

\section{Approach}

\section{Sample}

This descriptive survey research design examined the questions previously stated and used non-probability sampling of undergraduate nursing students and graduate nursing students from a nursing school in an Australian university. Inclusion criteria were that participants would be undergraduate nursing students, and graduate nurses who provided informed consent. Ethical approval was obtained from the relevant Human Research Ethics Committee prior to the commencement of the research (Table 2).

\section{Protocol}

For undergraduate participants $(\mathrm{N}=392)$, lecturers not directly involved in their study programme recruited students and distributed questionnaires at the commencement of term. Lecturers informed participants of the aims and objectives of the study, and reinforced that participation was voluntary. Completed questionnaires were returned to a sealed box and forwarded to the researchers. Questionnaires with an information letter, consent form and reply envelopes were forwarded to graduate participants $(\mathrm{N}=454)$. They returned them directly to the researchers. No prompts were provided to participants to return the questionnaire. The response rate was $14.1 \%(n=64)$ for alumni and $40 \%(n=153)$ for nursing students with a response rate for the study of $26.1 \%(n=217)$ overall.

\section{Measurement}

Questionnaire developed for an international study by Clark et al. (2004) was used to collect data (permission obtained). The survey contained 114 closed and open items in four sections: sociodemographic (4 items), attitudes to smoking (40 items), knowledge of smoking (38 items), and smoking behaviour ( 32 items). Attitudinal items were measured using a five point Likert scale. The open ended questions allowed participants to elaborate on their smoking behaviour.

Table 1

Health benefits of smoking cessation.

\begin{tabular}{ll}
\hline $20 \mathrm{~min}$ & BP and pulse rate return to normal \\
$8 \mathrm{~h}$ & Carbon Monoxide levels decrease by 50\%; \\
& oxygen levels return to normal \\
& No nicotine left in body, ability to taste and \\
& smell improves \\
& Breathing becomes easier, energy levels increase, \\
& bronchial tubes relax \\
$72 \mathrm{~h}$ & Circulation improves \\
& Heart attack risk drops to about 50\% of a smoker \\
$2-12$ weeks & Munafò et al., 2003 \\
\hline
\end{tabular}


Table 2

Participant demographics.

\begin{tabular}{|c|c|c|c|}
\hline & Student & Graduate & Total \\
\hline & $\mathrm{n}(\%)$ & $\mathrm{n}=(\%)$ & $\mathrm{n}(\%)$ \\
\hline Total & $153(70.5)$ & $64(29.5)$ & $217(100)$ \\
\hline \multicolumn{4}{|l|}{ Gender } \\
\hline Female & $135(88.2)$ & $56(87.5)$ & $191(88)$ \\
\hline Male & $18(11.8)$ & $8(12.5)$ & $26(12)$ \\
\hline \multicolumn{4}{|l|}{ Current employment } \\
\hline R.N. & $46(31.9)$ & $63(98.4)$ & $109(50.2)$ \\
\hline E.N & $17(11.8)$ & 0 & $17(8.2)$ \\
\hline E.N. & $2(1.4)$ & 0 & $2(1)$ \\
\hline A.I.N. & $37(25.7)$ & 0 & $37(17.8)$ \\
\hline Other & $42(29.2)$ & $1(1.6)$ & $43(20.7)$ \\
\hline \multicolumn{4}{|l|}{ Total length of time } \\
\hline Less than 12 months & $46(39.3)$ & $5(7.8)$ & $51(28.2)$ \\
\hline Between 12 months and 2 years & $20(17.1)$ & $11(17.2)$ & $31(17.1)$ \\
\hline Between 2 years and 5 years & $28(23.9)$ & $22(34.4)$ & $50(27.6)$ \\
\hline Between 5 years and 10 years & $13(11.1)$ & $10(15.6)$ & $23(12.7)$ \\
\hline More than 10 years & $10(8.5)$ & $16(25.0)$ & $26(14.4)$ \\
\hline \multicolumn{4}{|l|}{ Smoking status } \\
\hline No & $126(82.4)$ & $52(81.3)$ & $178(82)$ \\
\hline Yes & $27(17.6)$ & $12(18.8)$ & $39(18)$ \\
\hline
\end{tabular}

\section{Data Analysis}

Questionnaires were entered into SPSS and socio-demographic data was summarised using descriptive statistics. Factor analysis was undertaken to group the 27 items into scales. Principal components analysis (PCA) with varimax rotation was employed, eigenvalues and scree plots were examined to determine the number of factors included in the final analysis. Factor analysis was continued specifying a reduced number of factors and evaluating fit until four factors with clearly differentiated factors emerged. An item was assigned to a factor when its loading was greater than 0.33 and did not load on another factor, if an item did load on more than one factor it was not assigned to a factor. Overall scale scores were created for each factor by summing the scores of the included items and taking the mean, Chronbach's $\alpha$ was used to assess scale internal consistency. Independent t-tests or one way ANOVA were used to examine the differences in mean scores because of gender, age, student/graduate and smoking status (never smokes, past smoker and smoker).

\section{Results}

Factor analysis revealed four clearly differentiated factors, smoking rights ( 8 items), cessation beliefs ( 3 items), cessation attitudes ( 7 items) and therapeutic relationships (4 items) Table 1. Internal consistency of the non-smokers rights scale was $0.82,0.71$ for the cessation beliefs scale, 0.52 for the cessation attitudes scale and 0.73 for the therapeutic relationships scale.

Age

Significant differences were present in nurses' perceptions of smoking rights across age categories $(p=0.036)$, nurses aged $18-27(\bar{X}=3.44$, $S D=0.74)$ and $28-37(\bar{X}=3.54, S D=0.79)$ had significantly lower perceptions of smoking rights compared to those aged 48-59 ( $\bar{X}=4.01$, $S D=0.66)$. No significant differences were present across age categories for nurses' cessation beliefs $(p=0.229)$, cessation attitudes $(p=0.690)$ and therapeutic relationships $(p=0.519)$ (Table 3$)$.

\section{Gender}

No gender differences were observed between nurses' perceptions of smoking rights $(p=0.667)$, cessation beliefs $(p=0.846)$, cessation attitudes $(p=0.324)$ and therapeutic relationships $(p=0.923)$.
Table 3

Factor loadings for smoking attitudes.

\begin{tabular}{|c|c|c|c|c|}
\hline \multirow[t]{2}{*}{ Factor label } & \multicolumn{4}{|c|}{ Factor and loadings } \\
\hline & 1 & 2 & 3 & 4 \\
\hline \multicolumn{5}{|l|}{ Smoking rights (Smokers' vs non-smokers rights) $\alpha=0.82$} \\
\hline All nurses should be non-smokers. & 644 & & & \\
\hline $\begin{array}{l}\text { Patients should not be allowed to smoke at all in any } \\
\text { general health care facilities }\end{array}$ & .640 & & & \\
\hline $\begin{array}{l}\text { Patients should not be allowed to smoke at all in any } \\
\text { general health care premises }\end{array}$ & .760 & & & \\
\hline $\begin{array}{l}\text { Nurses who smoke should never be allowed to smoke } \\
\text { on duty. }\end{array}$ & .780 & & & \\
\hline It is right to ban smoking in public places. & 620 & & & \\
\hline Patients should have the right to smoke if they wish. & .729 & & & \\
\hline $\begin{array}{l}\text { Special facilities should be made for general patients to } \\
\text { smoke in health care facilities if they wish. }\end{array}$ & .509 & & & \\
\hline $\begin{array}{l}\text { Nurses should be allowed to smoke with their patients } \\
\text { while on duty. }\end{array}$ & .457 & & & \\
\hline \multicolumn{5}{|l|}{ Cessation beliefs $\alpha=0.71$} \\
\hline Too much fuss is made of the dangers of smoking. & & .73 & & \\
\hline $\begin{array}{l}\text { Patients who smoke have enough problems without } \\
\text { adding to them by asking them to give up smoking. }\end{array}$ & & .731 & & \\
\hline $\begin{array}{l}\text { People who have smoked for years should not be } \\
\text { encouraged to stop. }\end{array}$ & & .768 & & \\
\hline \multicolumn{5}{|l|}{ Cessation attitudes $\alpha=0.52$} \\
\hline All nurses should promote a healthy lifestyle. & & & .374 & \\
\hline It is extremely difficult to give up smoking. & & & 623 & \\
\hline $\begin{array}{l}\text { Nurses need specific knowledge to help someone to } \\
\text { stop smoking. }\end{array}$ & & & .396 & \\
\hline $\begin{array}{l}\text { Most young smokers have been influenced in their } \\
\text { smoking by their friends and peers. }\end{array}$ & & & .498 & \\
\hline $\begin{array}{l}\text { Children are more likely to begin smoking if one or } \\
\text { both parents smoke. }\end{array}$ & & & .454 & \\
\hline Most people put on weight once they stop smoking. & & & .330 & \\
\hline It is right to ban smoking advertising & & & .423 & \\
\hline \multicolumn{5}{|l|}{ Therapeutic relationships $\alpha=0.73$} \\
\hline Nurses who smoke should only smoke in their breaks & & & & .400 \\
\hline $\begin{array}{l}\text { Most patients can talk openly about smoking to a nurse } \\
\text { who smokes }\end{array}$ & & & & .563 \\
\hline $\begin{array}{l}\text { Nurses who smoke have more opportunities to interact } \\
\text { with patients who smoke. }\end{array}$ & & & & .847 \\
\hline $\begin{array}{l}\text { Nurses who don't smoke have decreased opportunities } \\
\text { to interact with patients who smoke. }\end{array}$ & & & & .820 \\
\hline
\end{tabular}

\section{Nursing Qualifications}

No significant differences were present between level of nursing qualification for smoking rights $(p=0.238)$, cessation beliefs $(p=$ $0.837)$, cessation attitudes $(p=0.326)$ or therapeutic relationships $(p=0.547)$.

\section{Smoking Status}

Current smokers had significantly lower perceptions of smoking rights $(\bar{X}=2.78, S D=0.62)$ compared to former smokers $(\bar{X}=3.57$, $\mathrm{SD}=0.79)$ and nurses who had never smoked $(\bar{X}=3.85, \mathrm{SD}=0.68$, $p \leq 0.001)$. Former smokers, who no longer smoked, also had significantly lower perceptions of smoking rights compared to those who had never smoked. Current smokers had lower perceptions of cessation beliefs $(\bar{X}=3.82, \mathrm{SD}=0.64)$ compared to former smokers $(\bar{X}=$ $4.09, \mathrm{SD}=0.66)$ and nurses who had never smoked $(\bar{X}=4.30, \mathrm{SD}=$ $0.72, p \leq 0.001$ ), current smokers also had significantly lower cessation beliefs compared to former smokers. No differences in cessation beliefs were present between nurses who had never smoked and former smokers. There were no differences in attitudes towards smoking cessation by smoking status ( $p=0.244)$.

Nurses who identified as current smokers $(\bar{X}=2.97, \mathrm{SD}=0.80)$ felt that they could develop a therapeutic relationship with smoking patients more so than that compared to former smokers $(\bar{X}=3.44$, $\mathrm{SD}=0.78)$ and nurses who had never smoked $(\bar{X}=3.35, \mathrm{SD}=0.77$, $p=0.010$ ). Former smokers reported that they had difficulty forming 
therapeutic relationships with patients who currently smoked compared to current smokers, but no differences were present between former smokers and those nurses who had never smoked.

\section{Limitations}

The response rate for this research (26.1\%) can be considered quite low. The study was also conducted with students from one university only and there was no pilot of the survey tool. As such the generalisability of findings needs to be done with caution.

\section{Discussion}

This paper reports on a descriptive survey research design that examined graduate nurses and nursing students' behaviour, knowledge and attitudes towards tobacco cessation. This study revealed that a high percentage of student nurses knew themselves to be in a prominent and influential position to assist hospitalised patients with tobacco cessation. Participants were aware of the role that they could play in smoking cessation and that as nurses they were in a strong position to influence patients behaviour and thus their health outcomes. Indeed, health care professionals are considered as role models by their patients (Ficarra et al, 2011) and in a study undertaken by Rush et al. (2005) nurses perceived that society expected them as role models, to be informational resources and to practice what they preached. Furthermore, this study revealed that student nurses' own behaviour toward smoking influenced their perceptions of how they could and would influence their patients smoking habits. This is consistent with previous research as described earlier in this paper.

The four clearly differentiated factors, non-smoker's rights, cessation beliefs, cessation attitudes and therapeutic relationships revealed that age was a factor in participant's beliefs about smoker's rights. Younger nurses, those aged between18-27 had significantly lower perceptions of smokers' rights compared to those aged 48-59. This is worthy of further research and could be a result of this age group being subjected to far greater public health campaigns about the negative effects of smokers than older Australians.

The development of a therapeutic relationship with a patient who is a smoker was easier to establish for clinicians who were themselves smokers. Therapeutic relationships influence how nurses engage with their clients and positive therapeutic relationships lead to better patient outcomes (Day et al., 2012). Building good relationships with patients is central to nursing work and clinicians who were smokers were more empathic of patients who currently smoked. Nurses who were former smokers, who one might have suspected would have a greater sense of understanding or empathy with patient's who smoked, felt that establishing a therapeutic relationship with a current smoker may be difficult. Perhaps this cohort felt that they had managed to quit smoking, and so should their patients?

Australian Bachelor of Nursing (BN) curriculums lack content related to preparing nursing students to provide adequate advice to patients in regards to their smoking habits. Studies have identified that medical students also lack basic knowledge about smoking and health and the effectiveness of cessation methods (Raupach et al., 2009). Exposure to education can affect clinicians' capacity to assist patients to cease smoking. Given the burden of disease related to smoking this study adds evidence to the growing body of knowledge that there is a link between behaviours, attitude and beliefs of clinicians regarding smoking cessation and their duty as role models and agents of change towards their patients. Other studies on nursing education and beliefs toward tobacco cessation identified that health professionals should receive formal training on smoking cessation, should act as role models to their patients and should provide advice so as to promote smoking cessation within hospital settings (Patelarou et al., 2011).

\section{Conclusion}

Health professionals, particularly nurses and nursing students who have regular and consistent patient contact play a considerable role in smoking prevention. Numerous studies have supported the efficacy of nurses in the delivery of tobacco cessation treatment. About half of all lifelong smokers die of smoking-related diseases. Given smoking is the single greatest cause of preventable illness and premature death, cessation should be encouraged by all health professionals in the execution of their duty of care. A planned cessation attempt is more likely to work than an impulsive one and nurses are clearly in a prime position to assist hospitalised patients establish and implement a personal plan to assist them to quit smoking.

Student and graduate nurses are aware that they are role models and that they have an influential role in modifying patient behaviour. When it comes to assisting patients to cease tobacco use, age and smoking status of nurses influence their actions. Nursing curriculums need to emphasise the role nurses play in smoking cessation and give them the tools they need to help patients QUIT. Data from the research outlined above can be used to inform education interventions for both nurses and nursing students about the importance and efficacy of cessation advice and current smoking cessation methods and practices with a view to helping hospitalised patients to cease smoking.

\section{References}

Attenbring, M., Hartford, M., Hjalmarson, A., Caidahl, K., Karlsson, T., Herlitz, J., 2004 Smoking habits and predictors of continued smoking in patients with coronary syndromes. Journal of Advanced Nursing 46 (6), 614-623.

Australian Institute of Health and Welfare, 2012. Tobacco Smoking. (Accessible from http://www.aihw.gov.au/risk-factors-tobacco-smoking/)

Baron-Epel, O., Josephsohn, K., Ehrenfeld, M., 2004. Nursing students' perceptions of smoking prevention. Nurse Education Today 24 (2), 145-151.

Cancer Council Victoria, 2012. QUIT. http://www.cancervic.org.au/preventing-cancer/ quit-smoking.

Carlebach, S., Hamilton, S., 2009. Understanding the nurse's role in smoking cessation. The British Journal of Nursing 18 (11), 672-676.

Central Public Health Unit Rockhampton, 1998. Ischaemic Heart Disease in Centra Queensland (incorporating Banana, Bundaberg, Central Highlands, Central west, Fraser Coast, Gladstone, North Burnett, Rockhampton and South Burnett Health Districts). Queensland Health, Queensland Government.

Chalmers, K., Seguire, M., Brown, J., 2003. Health promotion and tobacco control: student nurses' perspectives. Journal of Nurse Education 42 (3), 106-112.

Clark, E., McCann, T., Rowe, K., Lazenbatt, A., 2004. Cognitive dissonance and undergraduate nursing students' knowledge of, and attitudes about, smoking. Journal of Advanced Nursing 46 (6), 586-594.

Day, J., Levitt-Jones, T., Kenny, R., 2012. Communicating. In: Berman, A., Snyder, S.J., Levett-Jones, T., Dwyer, T., Hales, M., Harvey, N., Luxford, Y., Moxham, L., Park, T., Parker, T., Reid-Searl, K., Stanley, D. (Eds.), Fundamentals of Nursing: Second Australian Edition, vol. 2, pp. 521-557.

Doll, R., Peto, R., Boreham, J., Sutherland, I., 2004. Mortality in relation to smoking: 50 years' observations on male British doctors. British Medical Journal 328, 1519.

Dunn, P., 1998. Introduction - rural health and drug and alcohol dependence: double jeopardy. In: Griffiths, S., Dunn, P., Ramanathan, S. (Eds.), Drug and Alcohol Services in Rural and Remote Australia. The Gilmore Centre, Wagga Wagga.

Dwyer, T., Bradshaw, J., Happell, B., 2009. Comparison of mental health nurses' attitudes towards smoking and smoking behaviour. International Journal of Mental Health Nursing 18 (6), 424-433.

Ficarra, M.G., Gualano, M.R., Capizzi, S., Siliquini, R., Liguori, G., Manzoli, L., Briziarelli, L. Parlato, A., Cuccurullo, P., Bucci, R., Chiadò Piat, S., Masanotti, G., Chiara de Waure, C., Ricciardi, W., La Torre, G., 2011. Tobacco use prevalence, knowledge and attitudes among Italian hospital healthcare professionals. European Journal of Public Health 21 (1), 29-34

Gomm, M., Lincoln, P., Egeland, P., Rosenberg, M., 2002. Helping hospitalised clients quit smoking: a study of rural nursing practice and barriers. The Australian Journal of Rural Health 10, 26-32.

Hall, S., Vogt, F., Marteau, T.M., 2005. A short report: survey of practice nurses' attitudes towards giving smoking cessation advice. Family Practice 22 (6), 614-616.

Hughes, A., Rissel, C., 1999. Smoking: rates and attitudes among nursing staff in central Sydney. International Journal of Nursing Practice 5, 147-154.

Jenkins, K., Ahijevych, K., 2003. Nursing students' beliefs about smoking, their own smoking behaviors and use of professional tobacco treatment interventions. Applied Nursing Research 16 (3), 164-172.

Mitchell, J., Brown, J., Smith, C., 2009. Interprofessional education: a nurse practitioner impacts family medicine residents' smoking cessation counselling experiences. Journal of Interprofessional Care 23 (4), 401-409. 
Moxham, L., Arnold, T., Coutts, A., Michaels, A., Ray, R., 2000. Cardiovascular disease in regional Queensland: a case study identifying the implications for changing the primary health care educational paradigm. Australian Journal of Primary Health Interchange 6 (1), 1-11.

Myers, A.H., Rosner, B., Abbey, H., et al., 1987. Smoking behaviour among participants in the Nurses' Health Study. American Journal of Public Health 77, 628-630.

Munafò, M., Drury, M., Wakley, G., Chambers, R., 2003. Smoking Cessation Matters in Primary Care. Radcliff Medical Press, Oxon, UK.

Patelarou, E., Vardavas, C.I., Ntzilepi, P., Warren, C.W., Barbouni, A., Kremastinou, J. Connolly, G.N., Behrakis, P., 2011. Nursing education and beliefs towards tobacco cessation and control: a cross-sectional national survey (GHPSS) among nursing students in Greece. Tobacco Induced Diseases 9 (Sup. 1), 4-9.

Peto, R., Lopez, A., Boreham, J., Thun, M., Heath, C., 2000. Mortality from smoking: international comparison. British Medical Journal 320, 1102-1107.

Queensland Government, 2009. Queensland Drug Strategy, 2006-2010. Accessible from http://www.health.qld.gov.au/atods/documents/31976.pdf.

Queensland Health, 2004. Health Determinants Queensland. Queensland Government, Brisbane.
Raupach, T., Shahab, L., Baetzing, S., Hoffmann, B., Hasenfuss, G., West, R., Andreas, S., 2009. Medical students lack basic knowledge about smoking: findings from two European medical schools. Nicotine \& Tobacco Research 11 (1), 92-98.

Rowe, K., Clark, J.M., 2000. The incidence of smoking amongst nurses: a review of the literature. Journal of Advanced Nursing 31 (5), 1046-1053.

Rush, K.L., Kee, C.C., Rice, M., 2005. Nurses as imperfect role models for health promotion. Western Journal of Nursing Research 27 (2), 166-183.

Scanlon, A Clark, E. McGuiness, W, 2008. Acute (adult clinical inpatient) care nurses' attitudes towards and knowledge of nationally endorsed 5As smoking cessation guidelines. Contemporary Nurse 29 (1), 80-91.

Talbot, L., Verrinder, G., 2005. Promoting Health: The Primary Health Care Approach, 3rd ed. Elsevier, Sydney.

WHO (World Health Organisation), 1986. The Ottawa Charter for Health Promotion. Accessible from www.who. 